\section{High capacity vertical aligned carbon nanotube/sulfur composite cathodes for lithium-sulfur batteries $\dagger$}

\author{
Susanne Dörfler, ${ }^{a b}$ Markus Hagen, ${ }^{c}$ Holger Althues, ${ }^{a}$ Jens Tübke, ${ }^{c}$ Stefan Kaskel ${ }^{a b}$ and \\ Michael J. Hoffmann ${ }^{d}$
}

Received 19th December 2011, Accepted 28th February 2012

DOI: $10.1039 / \mathbf{c} 2 \mathrm{cc17925c}$

Binder free vertical aligned (VA) CNT/sulfur composite electrodes with high sulfur loadings up to $70 \mathrm{wt} \%$ were synthesized delivering discharge capacities higher than $800 \mathrm{mAh} \mathrm{g}^{-1}$ of the total composite electrode mass.

Sulfur cathodes potentially offer significant advantages over metal oxide and phosphate based electrodes for future generation lithium ion batteries. While the relatively low capacity of intercalation cathode materials (150-200 $\mathrm{mAh} \mathrm{g}^{-1}$ ) limits the energy density of today's lithium ion cells to about $200 \mathrm{Wh} \mathrm{kg}^{-1}$, the theoretical estimated capacity of elemental sulfur is $1672 \mathrm{mAh} \mathrm{g}^{-1}$ and thus energy densities larger than $350 \mathrm{Wh} \mathrm{kg}^{-1}$ are in reach for lithium-sulfur (Li-S) cells. ${ }^{1}$ Other advantages of sulfur are extremely low cost and widespread availability as well as enhanced safety aspects.

However, Li-S batteries still have not been commercialized yet, despite their promising properties. The so-called shuttle mechanism ${ }^{2}$ lowering the efficiency of Li-S cells by dissolution, migration and parasitic reactions of polysulfides during charging, and the poor electrical conductivity of elemental sulfur $\left(5 \times 10^{-30} \mathrm{~S} \mathrm{~cm}^{-1}\right)$, causing only low utilization of the active material, are still challenges that have to be overcome. Conducting carbon additives were found to significantly enhance the utilization of sulfur in various literature reports. ${ }^{3-9}$

In a typical approach a slurry is formulated based on elemental sulfur, a polymeric binder and carbon black dispersed in a solvent. ${ }^{3}$

\footnotetext{
${ }^{a}$ Fraunhofer Institute for Material and Beam Technology (IWS),

Winterbergstraße 28, Dresden, Germany.

E-mail: stefan.kaskel@iws.fraunhofer.de,

susanne.doerfler@iws.fraunhofer.de,

holger.althues@iws.fraunhofer.de; Fax: 004935183391 3300;

Tel: 0049351833913331

${ }^{b}$ Institute for Inorganic Chemistry I, Dresden, University of

Technology, Germany. Fax: 004935146334885

${ }^{c}$ Fraunhofer Institute for Chemical Technology (ICT),

Joseph-von-Fraunhofer-Str. 7, 76327 Pfinztal, Germany.

E-mail:markus.hagen@ict.fraunhofer.de,

jens.tübke@ict.fraunhofer.de; Fax:0049 7214640 318;

Tel: 00497214640716

${ }^{d}$ Karlsruhe Institute of Technology (KIT), Institute for Applied

Materials-Ceramics in Mechanical Engineering,

Haid-und-Neu-Straße 7, 76131 Karlsruhe, Germany.

E-mail: michael.hoffmann@kit.edu; Fax:0049 721608 48891;

Tel: 004972160844446

$\dagger$ Electronic supplementary information (ESI) available: Materials characterization and cell assembly. See DOI: $10.1039 / \mathrm{c} 2 \mathrm{cc} 17925 \mathrm{c}$
}

For electrode production, the slurry is applied on aluminum current collectors via a doctor blade technique or roll coating and finally dried and calendered. While carbon black is an efficient and established conductive additive, many other carbon materials have been recently reported to be advantageous in $\mathrm{Li}-\mathrm{S}$ cathodes. Ordered mesoporous carbons were found to offer a conducting framework encapsulating and contacting the sulfur. ${ }^{4}$ In combination with polyethylene glycol coatings the porous carbons were additionally found to inhibit the migration of polysulfides and thereby suppress the shuttle mechanism. Porous hollow carbons are another promising host material and cathodes based on hollow carbon@sulfur composites were reported to deliver stable discharge capacities of over $850 \mathrm{mAh} \mathrm{g}^{-1}$ (in terms of active sulfur mass) upon 100 cycles at $0.5 \mathrm{C}^{5}$ While porous carbons offer high utilization and stabilization of the sulfur, the overall energy density of resulting electrodes is reduced by the high carbon content (30 wt $\%$ ), the addition of binders (typically 5-10 wt \%) and the voids resulting from the interparticulate porosity.

Furthermore, one possible degradation mechanism of sulfur/ carbon composite cathodes is known to result from structural changes of the interparticle network as observed for carbon black in sulfur electrodes. ${ }^{6}$ During cycling, the uniform distribution of sulfur in the composite is lost resulting in decreased utilization and consequently in poor cycle life time. Carbon nanotubes (CNTs), when applied as a conductive additive in paste or slurry formulations, were found to be superior due to higher retention of the integrity of the conductive network caused by the high aspect ratio and the high intrinsic conductivity of CNTs. ${ }^{7-12}$

Similar to the electrodes from porous materials, the reported CNT/S composite electrodes typically have sulfur contents below $70 \mathrm{wt} \%$, as the paste formulations contain binders and other additives. The largest reported specific capacities related to the electrode mass ( $m_{\text {sulfur }}, m_{\text {carbon }}, m_{\text {binder }}$ and $\left.m_{\text {additives }}\right)$ are below $600 \mathrm{mAh} \mathrm{g}^{-1}$ both for CNT-S composites ${ }^{9}$ and for porous carbon- $\mathrm{S}$ composites ${ }^{4}$ (estimated from the average capacity values of the first 20 discharge cycles), while in many publications capacities are far below this value. Increasing the sulfur content in the electrode, while retaining its high utilization, is one of the challenging tasks to exploit the full potential of $\mathrm{Li}-\mathrm{S}$ batteries in terms of energy density.

Here we report a new approach based on binder free VA-CNT/ sulfur composite electrodes enabling high sulfur loadings up to 


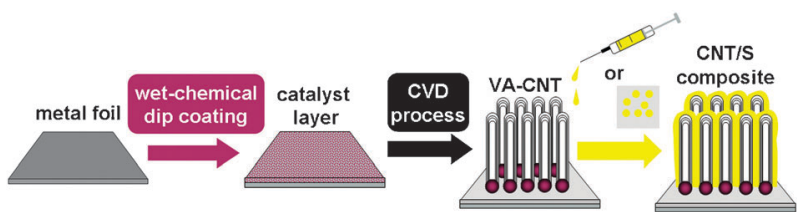

Fig. 1 Scheme of electrode preparation comprising the wet-chemical dip-coating step, the chemical vapor deposition and the sulfur infiltration by solution or melt infiltration.

$70 \mathrm{wt} \%$ and delivering discharge capacities higher than $800 \mathrm{mAh} \mathrm{g}^{-1}$ related to the composite electrode mass. This value significantly exceeds capacity values related especially to the composite mass from previous reports to the best of our knowledge.

In contrast to the common procedure of preparing the sulfur/ carbon composite by mixing and subsequent slurry coating, we start with the production of a VA-CNT electrode using chemical vapor deposition (CVD) on metallic substrates based on a process developed by Hata et al. ${ }^{13}$ For the VA-CNT growth, a catalyst thin film is deposited on metal foil by wet chemical techniques from organic metal salt solutions (Fig. 1, step 1).

The seeded substrate is transferred to the CVD chamber in a second step and CNT growth is performed at $730{ }^{\circ} \mathrm{C}$ using ethene as carbon precursor (Fig. 1, step 2). Details about the synthesis and the influence of catalyst composition and process parameters on the CNT film properties have been reported elsewhere. ${ }^{14}$ The resulting VA-CNT films are obtained as homogeneous black coatings on the nickel foil. In a typical experiment, the CNT films have a thickness of up to 100-200 $\mu \mathrm{m}$ (Fig. 2a) and a density of about $0.06-0.13 \mathrm{~g} \mathrm{~cm}^{-3}$. The individual CNTs are multiwalled and exhibit diameters of 7-30 nm. Due to the direct connection between each single CNT and the metal foil, the material offers a highly conductive and stable framework with an accessible inter-tube pore structure, while the metal foil acts as a current collector. To finally prepare CNT/S composite cathodes using this unique material architecture, elemental sulfur

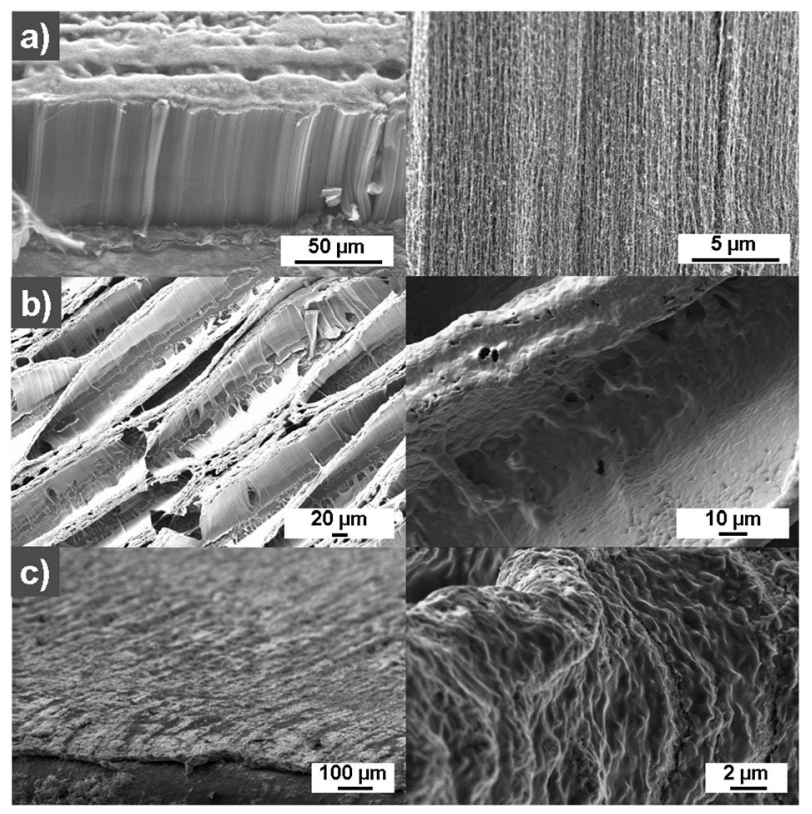

Fig. 2 SEM images of (a) as-deposited carbon nanotubes, (b) the sulfur/ VA-CNT composite electrode and (c) the as-cycled sulfur/VA-CNT composite electrode.

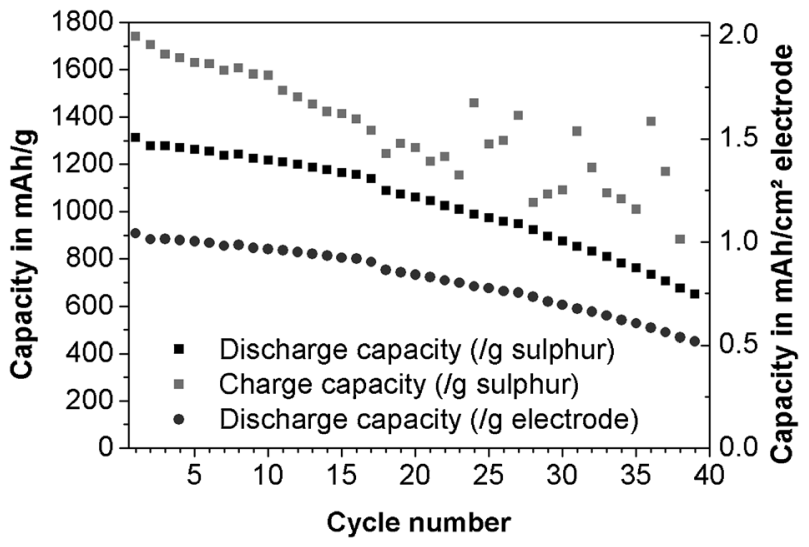

Fig. 3 Specific capacities (related to sulfur mass and electrode mass) vs. cycle number without $\mathrm{LiNO}_{3}$ addition in the electrolyte. The CNT/S composites have a sulfur content of $69 \%$.

is infiltrated in a subsequent step into the VA-CNT/Ni electrode (Fig. 1, step 3). Infiltration is achieved from sulfur solutions in toluene. SEM investigations indicate a complete and homogeneous infiltration of sulfur in the CNT network after melt infiltration, while capillary forces cause the formation of trenches and walls within the composite layer (Fig. 2b). Sulfur/carbon ratios up to 7:3 are obtained. TEM images (ESI $\dagger$, Fig. S1) reveal that the CNTs are covered by large amounts of amorphous sulfur. EDX (energy dispersive X-ray spectroscopy) mapping (ESI $\dagger$, Fig. S2) proves the homogeneous sulfur dispersion, as well.

Electrochemical cells are constructed from the $\mathrm{CNT} / \mathrm{S}$ composite cathodes, lithium anodes and separators, while a solution of $1 \mathrm{M}$ LiTFSI in DME:DIOX $(1: 1, \mathrm{v}: \mathrm{v})$ is selected as the electrolyte.

Fig. 3 shows the results of the cycling experiments using a charge and discharge rate of $\mathrm{C} / 13$. An electrode with $69 \mathrm{wt} \%$ sulfur content, as prepared by solution infiltration, has discharge capacities of over $1300 \mathrm{mAh} \mathrm{g}^{-1}$ (related to sulfur mass) and $800 \mathrm{mAh} \mathrm{g}^{-1}$ (related to composite mass) within the first cycles, representing a very high active mass utilization. In Fig. 2c SEM images of a CNT-S electrode after 20 cycles in the charged state are shown. The electrode was examined after disassembling the test cell in the glove box directly after $24 \mathrm{~h}$ of drying in the glove box. The VA-CNT film had a thickness of around $100 \mu \mathrm{m}$ before it was infiltrated by sulfur and pressed by the cell assembly to a height of about $20 \mu \mathrm{m}$. Assuming a theoretical mass density of $1.74 \mathrm{~g} \mathrm{~cm}^{-315}$ for a single MWNT and an average VA-CNT layer density of $0.1 \mathrm{~g} \mathrm{~cm}^{-3}$, the calculated free volume is about $94 \mathrm{vol} \%$. In the VA-CNT system, pores are formed by the tube interspaces.

When pressed to one fifth of the original volume, the free space between the tubes is reduced to $71 \mathrm{vol} \%$. This free volume is filled with sulfur to a very large extent, as $69 \mathrm{wt} \%$ sulfur in the composite corresponds to $65 \mathrm{vol} \%$ (assuming a sulfur density of $2.06 \mathrm{~g} \mathrm{~cm}^{-3}$ ).

After cycling the electrode film is coated by a fine layer that could be identified as elemental sulfur by Raman spectroscopy, ${ }^{16,17}$ with characteristic modes at $151 \mathrm{~cm}^{-1}, 217 \mathrm{~cm}^{-1}$ and $472 \mathrm{~cm}^{-1}$. The CNT network could still be identified through some gaps in the sulfur layer. Gaps are expected to be responsible for the operability of the electrode since they inhibit the complete isolation of the electrode by sulfur or 


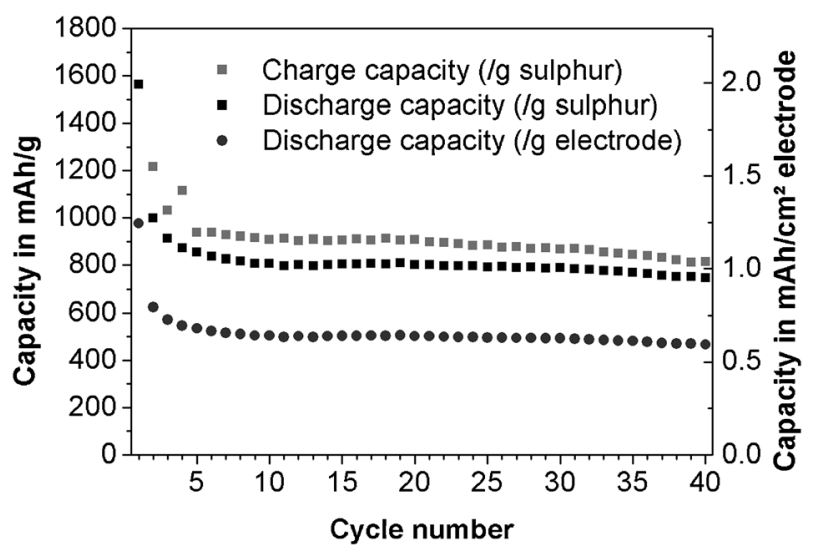

Fig. 4 Specific capacities (related to sulfur mass and electrode mass) vs. cycle number with $\mathrm{LiNO}_{3}$ addition in the electrolyte. The CNT/S composites have a sulfur content of $63 \%$.

$\mathrm{Li}_{2} \mathrm{~S}$ even at high sulfur loadings in the cell. The thickness of the sulfur layer is estimated to be below $50 \mathrm{~nm}$. SEM observations also indicate the CNT film to be intact, undamaged and still in contact with the current collector.

Large sulfur loadings, the absence of a binder and the high density of the electrode, together with the high sulfur utilization during cycling are clear advantages over existing electrode processing methods. In direct comparison with unoriented CNT/S composites, ${ }^{9}$ higher capacity values related to sulfur as well as to composite mass were obtained. However, the large differences between charge and discharge capacities indicate a low coulombic efficiency, and a remarkable degradation is observed over the first 40 cycles. These effects are expected to result from the polysulfide shuttle mechanism and side reactions at the metallic anode.

To enhance the charge/discharge efficiency, $\mathrm{LiNO}_{3}$ is used as electrolyte additive. $\mathrm{LiNO}_{3}$ is known to be reduced to $\mathrm{Li}_{x} \mathrm{NO}_{y}$ on $\mathrm{Li}$ and it oxidizes the sulfides to $\mathrm{Li}_{x} \mathrm{SO}_{y}$ species that passivate the $\mathrm{Li}$ electrode and thus prevent the continuous transport of electrons from Li to polysulfides in the electrolyte. ${ }^{18}$ The addition of $\mathrm{LiNO}_{3}(0.25 \mathrm{M})$ to the electrolyte leads to a much higher cycling stability and coulombic efficiency for an electrode with $63 \mathrm{wt} \%$ sulfur, clearly inhibiting the shuttle mechanism (Fig. 4). After large irreversible capacities in the first cycles, which can be attributed to the formation of the above-mentioned passivation layer, the capacity ranges between 800 and $900 \mathrm{mAh} \mathrm{g}^{-1}$ of sulfur and 500-600 $\mathrm{mAh} \mathrm{g}^{-1}$ of sulfur/VA CNT composite (Fig. 3).

In summary, a new binder-free electrode containing VA-CNTs, directly synthesized on a $\mathrm{Ni}$ current collector and subsequently infiltrated by sulfur was introduced as a promising choice for Li-S cells.

In cycling experiments discharge capacities higher than $800 \mathrm{mAh} \mathrm{g}^{-1}$ (mass of the composite) were demonstrated over 20 cycles. This value significantly exceeds results obtained from slurry made electrodes, especially with respect to the capacity per composite mass. SEM investigations before and after cycling revealed the CNT film provides a stabilizing, conducting network for the sulfur cathodes. As the soluble polysulfides are not retained actively by the electrode, its benefits are most suitably complemented by other mechanisms to shut off the shuttle mechanism as demonstrated exemplarily by applying the $\mathrm{LiNO}_{3}$ additive.

Adjusting the CNT-CVD process to deposit on aluminium or carbon substrates and thereby replacing nickel potentially enables even further improvement in terms of weight and costs of resulting electrodes. Preliminary experiments confirm the feasibility of CNT deposition on aluminium and carbon substrates and will be reported in separate publications. Due to improved performance of the electrodes, low cost precursors and scalable continuous processing, the synthesis-on-current collector strategy can be a competitive approach for electrode manufacturing.

This research was supported by the German Bundesministerium fuer Bildung und Forschung (BMBF) through the project Fraunhofer Systemforschung fuer Electromobilitaet (FSEM).

\section{Notes and references}

1 X. Ji and L. F. Nazar, J. Mater. Chem., 2010, 20, 9821-9826.

2 Y. V. Mikhaylik and J. R. Akridge, J. Electrochem. Soc., 2004, 151(11), A1969-A1976.

3 Y. S. Choi, S. Kim, S. S. Choi, J. S. Han, J. D. Kim, S. E. Jeon and B. H. Jung, Electrochim. Acta, 2004, 50, 833-835.

4 X. Ji, K. T. Lee and L. F. Nazar, Nat. Mater., 2009, 8, 500.

5 N. Jayaprakash, J. Shen, S. S. Moganty, A. Corona and L. A. Archer, Angew. Chem., Int. Ed., 2011, 50, 5904-5908.

6 B. H. Jeon, J. H. Yeon, K. M. Kim and I. J. Chung, J. Power Sources, 2002, 109, 89-97.

7 S.-C. Han, M.-S. Song, H. Lee, H.-S. Kim, H.-J. Ahn and J.-Y. Lee, J. Electrochem. Soc., 2003, 150, A889-A893.

8 W. Zheng, Y. W. Liu, X. G. Hua and C. F. Zhang, Electrochim. Acta, 2006, 51, 1330-1335.

9 L. Yuan, H. Yuan, X. Qiu, L. Chen and W. Zhu, J. Power Sources, 2009, 189, 1141-1146.

10 J.-J. Chen, X. Jia, Q.-J. She, C. Wang, Q. Zhang, M.-S. Zheng and Q.-F. Dong, Electrochim. Acta, 2010, 55, 8062-8066.

11 W. Wei, J. Wang, L. Zhou, J. Yang, B. Schumann and Y. Nu Li, Electrochem. Commun., 2011, 13, 399-402.

12 L. Yin, J. Wang, J. Yang and Y. Nuli, J. Mater. Chem., 2011, 21, 6807.

13 K. Hata, D. N. Futaba, K. Mizuno, T. Namai, M. Yumura and S. Iijima, Science, 2009, 306, 1362.

14 S. Dörfler, A. Meier, S. Thieme, P. Németh, H. Althues and S. Kaskel, Chem. Phys. Lett., 2011, 511, 288-293.

15 S. H. Kim, G. W. Mulholland and M. R. Zachariah, Carbon, 2009, 47, 1297-1302.

16 J. Wang, S. Y. Chew, Z. W. Zhao, S. Ashraf, D. Wexler, J. Chen, S. H. Ng, S. L. Chou and H. K. Liu, Carbon, 2008, 46, 229.

17 G. Eckhardt, D. P. Bortfeld and M. Geller, Appl. Phys. Lett., 1963, 3, 8 .

18 D. Aurbach, E. Pollak, R. Elazari, G. Salitra, C. Scordilis Kelley and J. Affinito, J. Electrochem. Soc., 2009, 156(8), A694-A702. 